\title{
Ferrara Intrastromal Corneal Ring Segments
}

\author{
${ }^{1}$ Leonardo Torquetti, ${ }^{2}$ Jordana Sandes, ${ }^{3}$ Guilherme Ferrara, ${ }^{4}$ Paulo Ferrara
}

\begin{abstract}
The Ferrara intrastromal corneal ring segments (ICRS) are designed to treat ectatic corneal disorders, especially keratoconus. They have been used to reshape keratoconic corneas to improve uncorrected visual acuity, best-corrected visual acuity, contact lens tolerance and to delay or prevent the need for keratoplasty. Intrastromal corneal ring segments have several distinct and important advantages. The Ferrara ICRS have been used largely in several countries for the treatment of primary and secondary ectatic corneal disorders. This article reviews the latest data published and the clinical experience/findings on the treatment of keratoconus by the Ferrara ICRS implantation.
\end{abstract}

Keywords: Ferrara, Intrastromal corneal ring segments, Keratoconus.

How to cite this article: Torquetti L, Sandes J, Ferrara G, Ferrara P. Ferrara Intrastromal Corneal Ring Segments. Int J Kerat Ect Cor Dis 2016;5(3):114-127.

\section{Source of support: Nil}

Conflict of interest: Dr. Paulo Ferrara and Guilherme Ferrara have proprietary interest in the Ferrara ICRS. Dr. Leonardo Torquetti does not have financial interest in any device cited in this review.

\section{INTRODUCTION}

The implantation of intrastromal corneal ring segments (ICRS) is a minimally invasive surgical option for reshaping the cornea in keratoconus and other secondary ectasias. Intrastromal corneal ring segments have been used to correct ectatic corneal diseases in order to reduce corneal steepening and irregular astigmatism and improve the visual acuity. ${ }^{1-6}$ Besides, the ICRS are a surgical alternative to at least delay, if not eliminate, the need for lamellar keratoplasty or penetrating keratoplasty (PKP).

In 1986, Ferrara started implanting modified polymethylmethacrylate (PMMA) ICRS in rabbit corneas, and in 1994, he developed a better technique of corneal tunnel construction for implanting the ICRS. ${ }^{8}$

The Ferrara ICRS are made of PMMA Perspex camphorquinone (CQ) acrylic segments. They vary in

\footnotetext{
${ }^{1,4}$ Head, ${ }^{2,3}$ Assistant Surgeon

${ }^{1}$ Department of Ophthalmology, Center for Excellence in Ophthalmology, Pará de Minas, Brazil

${ }^{2}$ Department of Ophthalmology, Center of Reference in Ophthalmology, Goiânia, Brazil

${ }^{3,4}$ Department of Ophthalmology, Paulo Ferrara Eye Clinic Belo Horizonte, Brazil
}

Corresponding Author: Leonardo Torquetti, Head, Department of Ophthalmology, Center for Excellence in Ophthalmology, Pará de Minas, Brazil, e-mail: leonardo@ceoclinica.med.br thickness and are available in $0.15,0.20,0.25$, and $0.30 \mathrm{~mm}$. The segment cross-section is triangular, and the base for every thickness and diameter is $0.60 \mathrm{~mm}$. The segments have $90,120,140,160$, or $210^{\circ}$ of arc.

Many studies have demonstrated the efficacy of ICRS to treat many corneal conditions as keratoconus, ${ }^{1-7}$ post-LASIK corneal ectasia, ${ }^{9,10}$ postradial keratotomy ectasia, ${ }^{11}$ astigmatism, ${ }^{12}$ and myopia. ${ }^{13-15}$ The changes in corneal structure induced by additive technologies can be roughly predicted by Barraquer's thickness law, which states that when material is added to the periphery of the cornea or an equal amount of material is removed from the central area, a flattening effect is achieved. The corrective result varies in direct proportion to the thickness of the implant and in inverse proportion to its diameter. The thicker and smaller is the diameter of the device, the higher is the corrective result. ${ }^{16}$

Preliminary investigations have demonstrated that ICRS are effective in the treatment of astigmatism and myopia with astigmatism, with the preservation of corrected distance visual acuity (CDVA) and stable results over time. ${ }^{2,17-20}$ The objective of the addictive technology is to reinforce the cornea, decrease the corneal irregularity, and provide improvement of visual acuity in affected patients.

The research about the Ferrara ICRS began in 1985. In 1986, Dr. Paulo Ferrara (P.F) realized that to keep the implant in place, a large hole was needed in the center of the lens which resulted in an annular prostheses. Since then, several annular shapes and diameters were tried. From these researches, it was concluded that the best design would be the one, i.e., used nowadays, made of PMMA, with a total diameter of $5.0 \mathrm{~mm}$, arch length ranging from 90 to $210^{\circ}$, and thickness ranging from 150 to $300 \mu \mathrm{m}$.

The ICRS were implanted in rabbit eyes, through a free hand dissection technique, at $50 \%$ depth of measured central corneal thickness. The eyes were examined for 12 months, and the animals were sacrificed for histopathological exams. The histopathological results revealed excellent tolerance of the cornea to the orthesis since there was only slight inflammatory reaction surrounding the implant and no evidence of extrusion.

The techniques, traditionally, used for the implant of corneal prostheses, free hand dissection, and keratectomy with a microkeratome showed some negative points, such as interface deposits, delay in refractive stability, 
besides the high costs of microkeratomes and slow learning curves.

In order to improve the ICRS implantation technique, reduce its complications, and make it accessible to a large number of anterior segment surgeons, we (P.F) developed in 1994 a stromal tunnel and ICRS implantation technique, which completely eliminates the disadvantages of the conventional techniques.

In 1995, we (P.F) implanted the first patient who had undergone PKP and radial keratotomy. This patient was forwarded to the Cornea Service at Hospital Sao Geraldo in Federal University of Minas Gerais (UFMG) for a new transplantation. We decided, with formal authorization of the patient, to test the ICRS before performing the PKP. The result was satisfactory, yielding ametropia correction and good corneal tolerance to the orthesis.

The excellent tolerance to the implant by the transplanted cornea gave us the needed confidence to apply the technique in keratoconic corneas. Therefore, we decided in 1996, to implant the ICRS in patients' intolerant to contact lenses that had the PKP indicated.

\section{MECHANISM OF ACTION}

The ICRS complies with Barraquer and Blavatskaya postulates, according to which, an addition in the cornea periphery results in its flattening, and the ICRS diameter determines how much the cornea will be flattened. Thus, the more tissue is added (increasing ICRS thickness), and the smaller is the diameter, the greater will be the myopia correction obtained. ${ }^{21,22}$

Besides these mechanisms of action, there are some additional changes induced by the ICRS:

- Regularization of the corneal surface through a tilting movement caused by the flatness in the surface of the ICRS base, making the cornea flattened at the areas corresponding to the segment extremities and making it curve at the ICRS body area.

- Interruption, or at least delay of keratoconus evolution, ${ }^{17,19}$ reduction of opacity on the cone apex, and reduction of related symptoms as itching, photophobia, and pain/ocular discomfort.

- Lack of correspondence between uncorrected visual acuity after the ICRS implantation and residual ametropia. Sometimes, good visual acuity coexisting with high residual refractive errors can be observed.

- The prisma effect generated by the triangular section reduces halos and glare, which could result from the small diameter of the orthesis.

- The yellow filter introduced in the plastic prevents the ultraviolet (UV) light to go into the eye, reducing the halos and reflections at night.
Table 1: Ferrara ICRS indications

\begin{tabular}{ll}
\hline 1 & Keratoconus \\
2 & High irregular astigmatism after PKP or lamellar keratoplasty \\
3 & Irregular astigmatisms after radial keratotomy \\
4 & Pellucid marginal degeneration \\
5 & Corneal ectasia after excimer laser
\end{tabular}

\section{INDICATIONS}

The main indication for the Ferrara ICRS implantation is keratoconus. In patients with keratoconus, the Ferrara ICRS should be indicated when: (1) There is an evidence of progressive worsening of the disease, with the gradual decrease of UDVA and CDVA; (2) progressive corneal steepening, and (3) progressive contact lens intolerance.

In post-LASIK corneal ectasia, ${ }^{9}$ the Ferrara ICRS implantation is indicated when there is worsening of the condition. The main indications for the Ferrara ICRS implantation are listed in Table 1.

\section{CONTRAINDICATIONS}

The main contraindications for the Ferrara ICRS implantation are the presence of apical opacities in very advanced keratoconus, usually with $\mathrm{K}$ readings above 60 Diopters (D). The postoperative results in these cases are usually poor, and the best treatment for these cases is lamellar keratoplasty or PKP. ${ }^{8,23}$ The main contraindications for the Ferrara ICRS implantation are listed in Table 2.

\section{NOMOGRAM}

The nomogram has evolved as the knowledge about the predictability of results has grown. Initially, surgeons implanted a pair of symmetrical segments in every case. The incision was always placed on the steep meridian to take advantage of the coupling effect achieved by the ICRS.

First, only the grade of keratoconus was considered for the ICRS selection, which means that in keratoconus grade I, the more suitable Ferrara ICRS for implantation was that of $150 \mu \mathrm{m}$, and in keratoconus grade IV, the more appropriate ICRS was of $350 \mu \mathrm{m}$ (Table 3). However, some cases of extrusion could be observed in keratoconus grade IV in which the cornea is usually very thin, and the thick ICRS sometimes were not properly fitted into the corneal stroma.

Table 2: Ferrara ICRS contraindications

\footnotetext{
1 Very advanced keratoconus with curvatures over $60 \mathrm{D}$ and significant apical opacity and scar ICRS

2 Hydropsis

3 Thin corneas, with thickness below $300 \mu \mathrm{m}$ in the ICRS track

4 Patients with intense atopia (these should be treated before the implant)

5 Any ongoing infectious process, local or systemic
} 
Table 3: Ferrara ICRS first-generation nomogram

\begin{tabular}{lll}
\hline Diameter $5.00 \mathrm{~mm}$ & Thickness $(\mathrm{mm})$ & Diopters to be corrected \\
\hline Fruste & 0.150 & -2.00 to -4.00 \\
Cone I & 0.200 & -4.25 to -6.00 \\
Cone II & 0.250 & -6.25 to -8.00 \\
Cone III & 0.300 & -8.25 to -10.00 \\
Cone IV & 0.350 & -10.25 to -12.00 \\
\hline
\end{tabular}

The second generation of the nomogram considered the refraction for ICRS selection, besides the distribution of the ectatic area on the cornea. Therefore, as the spherical equivalent increased, the selected ICRS thickness also increased. However, in many keratoconus cases, the myopia and astigmatism could not be caused by the ectasia itself but by an increase in the axial length of the eye (axial myopia). In these cases, hypercorrection by implanting a thick ICRS was observed in a keratoconus in which a thinner segment should be indicated.

In the third generation of the Ferrara ICRS nomogram, the ICRS selection depends on the type of keratoconus, its location in the cornea (Table 4), topographic astigmatism (Tables 5 to 7), and pachymetry. ${ }^{17,24}$

Table 4: Distribution of the area of corneal ectasia

\begin{tabular}{|c|c|c|}
\hline Map & $\begin{array}{l}\text { Distribution } \\
\text { of ectasia }\end{array}$ & Description \\
\hline & 0/100\% & $\begin{array}{l}\text { All the ectatic area is located at one } \\
\text { side of the cornea }\end{array}$ \\
\hline & $25 / 75 \%$ & $\begin{array}{l}75 \% \text { of the ectatic area is located at } \\
\text { one side of the cornea }\end{array}$ \\
\hline & $33 / 66 \%$ & $\begin{array}{l}66 \% \text { of the ectatic area is located at } \\
\text { one side of the cornea }\end{array}$ \\
\hline & $50 / 50 \%$ & $\begin{array}{l}\text { The ectatic area is symmetrically } \\
\text { distributed on the cornea }\end{array}$ \\
\hline
\end{tabular}

Table 5: Segment thickness choice in symmetric bow-tie keratoconus

\begin{tabular}{ll}
\hline Topographic astigmatism $(D)$ & Segment thickness \\
\hline$<1.00$ & $150 / 150$ \\
$1.25-2.00$ & $200 / 200$ \\
$2.25-3.00$ & $250 / 250$ \\
$>3.25$ & $300 / 300$ \\
\hline
\end{tabular}

Table 6: Asymmetrical segment thickness choice in sag cones with $0 / 100$ and $25 / 75 \%$ of asymmetry index (Graph 1)

\begin{tabular}{ll}
\hline Topographic astigmatism $(D)$ & Segment thickness \\
\hline$<1.00$ & none/150 \\
$1.25-2.00$ & none/200 \\
$2.25-3.00$ & none/250 \\
$3.25-4.00$ & none/300 \\
$4.25-5.00$ & $150 / 250$ \\
$6.25-6.00$ & $200 / 300$ \\
\hline
\end{tabular}

For symmetric bow-tie patterns of keratoconus, two equal segments are selected. For the nipple type of keratoconus, a single $210 \mu \mathrm{m}$ segment is chosen based on the nomogram (Table 8). For peripheral cones, the most common type asymmetrical segments are selected. It is important to emphasize that the ICRS thickness cannot exceed $50 \%$ of the thickness of the cornea on the track of the ICRS.

Using this third generation of the nomogram, we usually found that in some patients, there was significant corneal flattening without considerable improvement of visual acuity. We realized that, in these cases, the cornea usually presented oblate (positive $Q$ values) postoperatively, what could explain the lack of significant improvement in these cases. ${ }^{25-27}$

This finding led us to retrospectively review the charts of 147 eyes operated in 2008, and we evaluated the asphericity changes induced by the implantation of each thickness of ICRS (or pair of ICRS). Surprisingly, we found a direct correlation between ICRS thickness and change of $Q$ values; i.e., the thicker is the ICRS the more is the effect in the change of $Q$ value.

One paper published by our group ${ }^{27}$ showed that, using the previous nomograms, the CDVA was 20/60 or better in $70 \%$ of patients. When using the Q-based nomogram, we found a CDVA of $20 / 40$ or better in $70 \%$ of patients.

The asphericity should be the first parameter to be considered in the ICRS selection. However, all the other parameters are considered secondarily (topographic astigmatism and pachymetry).

We have described ${ }^{27}$ that for each ICRS segment, there is a correspondent $Q$ value change (Graph 1). A target postoperative $Q$ value as close as possible of -0.23 is the goal after the Ferrara ICRS implantation. ${ }^{28-30}$ Based on this nomogram, one could predict the $Q$ value change after the implantation of a specific ICRS (or pair of ICRS)

Table 7: Asymmetrical segment thickness choice in sag cones with $0 / 100$ and $33 / 66 \%$ of asymmetry index (Graph 1)

\begin{tabular}{ll}
\hline Topographic astigmatism $(D)$ & Segment thickness \\
\hline$<1.00$ & none/150 \\
$1.25-2.00$ & $150 / 200$ \\
$2.25-3.00$ & $200 / 250$ \\
$3.25-4.00$ & $250 / 300$ \\
\hline
\end{tabular}

Table 8: Segment thickness choice in Nipple cones $(210 \mu \mathrm{m}$ ICRS)

\begin{tabular}{ll}
\hline Spherical equivalent $(D)$ & Segment thickness \\
\hline Up to 2.00 & 150 \\
$2.25-4.00$ & 200 \\
$4.25-6.00$ & 250 \\
$>6.25$ & 300 \\
\hline
\end{tabular}




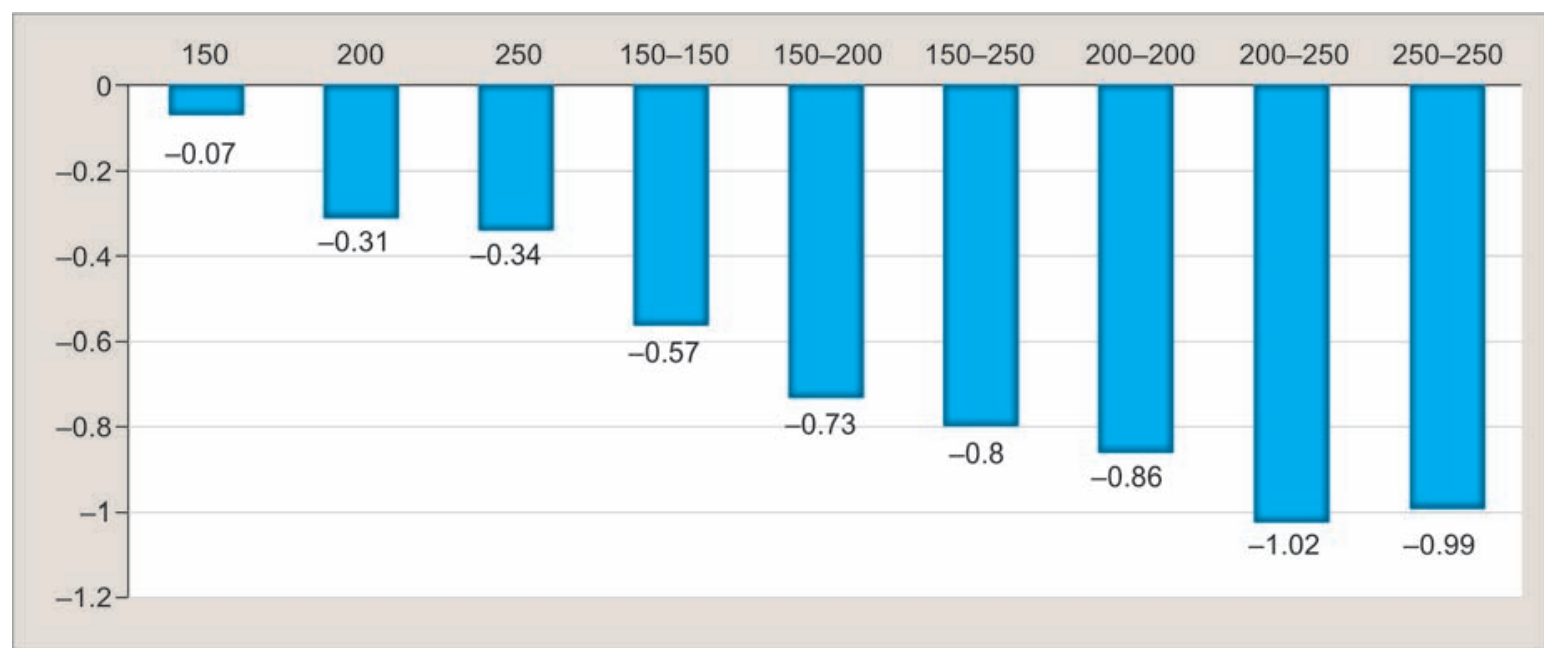

Graph 1: Q (asphericity) variation according to the ICRS thickness (160-arc ICRS)

Table 9: Actual Ferrara ICRS nomogram (Q-based): step-by-step

\begin{tabular}{ll}
\hline 1 Define the keratoconus type: sag, bow-tie, or nipple \\
2 Corneal asphericity $(\mathrm{Q})$ \\
3 Pachymetry at incision site and ICRS track \\
\hline
\end{tabular}

thickness; e.g., a single segment of $200 \mu \mathrm{m}$ changes the asphericity as 0.31 (Graph 1); therefore, this segment would be the most appropriate in patients with a preoperative $Q$ value of -0.54 , to achieve a postoperative $Q$ value close to -0.23 (theoretical normal value). ${ }^{28-30}$

The pachymetry at the incision site (steep axis of the cornea) must be determined. The incision depth must be $80 \%$ of the corneal thickness at the incision site. The pachymetry should be measured in all ICRS track to avoid superficial ICRS, which could lead to future extrusion.

The actual guidelines for ICRS selection are described in Table 9.

\section{SURGICAL TECHNIQUE}

\section{Manual Technique}

The surgery is performed under topical anesthesia after miosis is achieved with $2 \%$ pilocarpine. An eyelid speculum is used to expose the eye, and 2.5\% of povidone-iodine eye drops is instilled in the cornea and conjunctival cul-de-sac. The visual axis is marked by pressing the Sinskey hook on the central corneal epithelium while asking the patient to fixate on the corneal light reflex of the microscope light. Using a marker tinted with gentian-violet ink, a 5.0-mm optical zone and incision site are aligned to the desired axis in which the incision will be made. This site can be the steepest topographic axis of the cornea (in case of implantation of two segments) or $90^{\circ}$ (in case of implantation of only one segment - one of the tips of the ICRS must be located on the steepest axis). ${ }^{17}$
The depth of a 1.0-mm square diamond blade is set at $80 \%$ of corneal thickness at the incision site, and this blade is used to make the incision. Using a "stromal spreader," a pocket is formed in each side of the incision. Two (clockwise and counterclockwise) $270^{\circ}$ semicircular dissecting spatulas are consecutively inserted through the incision and gently pushed with some, quick, rotary "back and forth" tunneling movements. Following channel creation, the ICRS are inserted using a modified McPherson forceps. The ICRS are properly positioned with the aid of a Sinskey hook.

\section{Femtosecond Laser Technique}

The femtosecond laser (IntraLase Corp.) has recently been introduced in clinical practice whose surgical effect through photodisruption can be used as an alternative to the traditional mechanical techniques. Several recent articles $^{31-36}$ have reported its efficacy and safety for tunnel creation and intrastromal ICRS implantation. The femtosecond laser can easily and quickly create a predetermined depth and channel size.

There is a controversy over channel size nomograms with the technique. Some authors conclude that more effect can be achieved by making the stromal channels narrower than the ICRS size, leading to faster visual results. ${ }^{37}$

The use of the femtosecond laser in corneal tunnel creation made the procedure faster, easier (especially for inexperienced surgeons), and more comfortable for the patient. However, the main advantage of IntraLaseassisted channel creation over the mechanical technique seems to be the precise depth of implantation. The only disadvantage of this technique is the cost of the equipment, which is still relatively high.

The technique: Tunnel depth is set at $80 \%$ of the thinnest corneal thickness on the tunnel location in the femtosecond laser. Special attention must be given in centralizing the disposable suction ICRS to mark the 
central point to minimize decentration. The channel's inner diameter is set to $4.4 \mathrm{~mm}$, the outer diameter is $5.6 \mathrm{~mm}$, the entry cut thickness is $1 \mathrm{~m}$ (at the steepest topographic axis), the ICRS energy used for channel creation is 1.30j, and the entry cut energy is $1.30 \mathrm{j}$. Channel creation timing with the femtosecond laser is 15 seconds. The intracorneal ICRS are implanted immediately after the channel creation before the disappearance of the bubbles, which reveals the exact tunnel location. The segments are placed in the final position with a Sinskey hook through a dialing hole at both ends of the segment.

The postoperative regimen, for both techniques, consists of moxifloxacin $0.5 \%$ (Vigamox ${ }^{\circledR}$, Alcon, USA) and dexamethasone $0.1 \%$ (Maxidex ${ }^{\circledR}$, Alcon, USA) eye drops four times per day for 2 weeks. The patients were instructed to avoid rubbing the eye and to use preservative-free artificial tears frequently - polyethylene glycol $4000.4 \%$ (Oftane ${ }^{\circledR}$, Alcon, USA).

\section{Manual ×Femtosecond Laser Technique}

Initially, the tunnel for ICRS implantation was created manually with a mechanical spreader in every case. The complications of ICRS implantation with mechanical devices include epithelial defects, perforation, asymmetric segment placement, and extension of the incision toward the central visual axis or the limbus. ${ }^{38-41}$

More recently, surgeons began using a femtosecond laser to create the tunnel. It has been proposed that this method results in precise tunnel and keratotomy depth, width, and location as well as a uniform $360^{\circ}$ channel; causes minimum haze and edema; and minimizes surgical complications. The femtosecond laser acts through photodisruption and can be programmed to create tunnels for segment placement at predictable corneal depths. Studies show that tunnel creation with the femtosecond laser is easier, more precise, and more predictable than with the traditional mechanical spreaders. ${ }^{36}$

Some studies have compared the visual and refractive outcomes and the complications of mechanical tunnel creation and femtosecond-assisted tunnel creation for ICRS implantation to manage keratoconus. ${ }^{31,33,42,43}$

The results of these clinical trials suggest that visual and refractive results of femtosecond-assisted tunnel creation are comparable to those of mechanical tunnel creation. ${ }^{31}$ However, the femtosecond method is faster, easier, and more comfortable for both patient and surgeon. Another potential advantage of the femtosecond method is the precise depth of implantation, especially in thinner corneas.

\section{LONG-TERM FOLLOW-UP AFTER FERRARA ICRS IMPLANTATION IN KERATOCONUS}

We retrospectively reviewed patient records of 94 eyes of 76 patients, which were consecutively operated
(Ferrara ICRS implantation). ${ }^{17}$ There were 33 females and 61 males. The average age of the patients was 28.1 years. All procedures were performed by the same surgeon (P.F) between June 1996 and September 2007. Patients included in the study presented clear cornea and a minimal corneal thickness of $300 \mu \mathrm{m}$ at the ICRS track. Patients were intolerant to contact lens and/or showed progression of ectasia.

Fifty-eight subjects underwent a single eye treatment, whereas 18 subjects had both eye treated. Seventy-three eyes had a 2-year follow-up, 66 eyes had a 3-year follow-up, 48 eyes had a 4 -year follow-up, and 34 eyes had a 5 -year follow-up. All patients completed at least a 2-year follow-up. No intraoperative complications occurred. All patients returned for ocular examination on day one, 1 week and a month after the surgery, and then 3, 6, and 12 months. Thereafter, the following eye examinations occurred yearly.

Preoperative and postoperative UDVA, CDVA, and keratometry data were collected from all patients. The mean UDVA (decimal) at the preoperative period was 0.12 , and the mean CDVA (decimal) was 0.41. At the first month, the mean UDVA improved to 0.25 , and the mean CDVA improved to 0.56. At 2-year follow-up, the mean UDVA improved from 0.12 preoperatively to 0.29 . At 3-year follow-up, the mean UDVA improved to 0.34 , at 4 -year follow-up, the mean UDVA improved to 0.42 , and at 5-year follow-up, the mean UDVA decreased to 0.31 postoperatively. The mean CDVA, at the first month, improved to 0.56. At 2-year follow-up, the mean CDVA improved from 0.41 preoperatively to 0.68 . At the third-year follow-up, the mean CDVA decreased to 0.63; at the fourth-year follow-up, the mean CDVA improved to 0.65 ; and at the fifth-year follow-up, the mean CDVA decreased to 0.59 postoperatively.

The mean keratometry decreased significantly from the preoperative to the last postoperative follow-up. Preoperative mean keratometry was 50.36 , which decreased to 47.29 at the first-month postoperative follow-up. The mean keratometry follow-up along the second to fifth years was $45.96,45.83,46.44$, and 46.24 respectively.

As shown in previous studies, the intrastromal ICRS flatten the cornea and keep this effect for a long period of time. There is no significant resteepening of the cornea over time.

A study published by Pesando et $\mathrm{al}^{44}$ found similar results in a 5-year follow-up. A total of $93.84 \%$ (122 patients) of the eyes gained lines of UDVA, and only $1.53 \%$ (2 eyes) lost them. A total of $97.69 \%$ (127 patients) of the treated eyes gained lines of CDVA, and no eyes lost them. The values of $\mathrm{K} 1$ and $\mathrm{K} 2$ were considerably reduced over 5 years. The preoperative value of $\mathrm{K}$ average of $49.27 \mathrm{D}$ became 4.68 D postoperatively. Both UDVA and the CDVA 
showed an increase. The UDVA changed from 0.14 lines preoperatively to 0.32 lines postoperatively, while the best-corrected visual acuity (BCVA) changing from 0.40 to 0.59 . The spherical equivalent changed from $-8.34 \mathrm{D}$ before the operation to $-2.83 \mathrm{D}$ after the operation.

In 2014, we published a paper ${ }^{19}$ with the longest followup ever described, after ICRS implantation. The mean UDVA (logMAR) improved from $1.01 \pm 0.28$ to $0.71^{\circ} \pm{ }^{\circ} 0.38$ at 5 years $(p=0.000)$ and $0.67^{\circ} \pm^{\circ} 0.25$ at 10 years $(p=0.735)$. The mean CDVA (logMAR) improved from $0.45^{\circ} \pm{ }^{\circ} 0.45$ to $0.24^{\circ} \pm{ }^{\circ} 0.19$ at 5 years $(\mathrm{p}=0.004)$ and $0.29^{\circ} \pm{ }^{\circ} 0.09$ at 10 years $(p=0.292)$. The mean maximum $K$ value decreased from $54.99^{\circ} \pm{ }^{\circ} 6.33$ to $50.58^{\circ} \pm{ }^{\circ} 5.11 \mathrm{D}$ at 5 years $(\mathrm{p}=0.000)$ and $50.65^{\circ} \pm{ }^{\circ} 5.17 \mathrm{D}$ at 10 years $(\mathrm{p}=0.854)$. The mean minimum $\mathrm{K}$ value decreased from $48.85^{\circ} \pm{ }^{\circ} 5.70$ to $46.90^{\circ} \pm{ }^{\circ} 5.08$ $\mathrm{D}$ at 5 years $(\mathrm{p}=0.000)$ and $47.12^{\circ} \pm{ }^{\circ} 4.22 \mathrm{D}$ at 10 years $(p=0.945)$. The central corneal thickness decreased from $457.42^{\circ} \pm{ }^{\circ} 58.21$ to $421.34^{\circ} \pm{ }^{\circ} 74.12 \mu \mathrm{m}$ at 5 years $(\mathrm{p}=0.039)$ and $434.32^{\circ} \pm^{\circ} 77.65 \mu \mathrm{m}$ at 10 years $(\mathrm{p}=0.427)$.

These studies showed that the Ferrara ICRS could be a valuable tool to provide topographic and visual stability, delay the progression of keratoconus, and postpone a corneal grafting surgery to more physiological position. ${ }^{4,18}$

\section{THE 140 FERRARA ICRS}

There are different models of Ferrara ICRS with varying sizes and arc thickness. These segments induce an arch shortening effect in the lamella, leading to central flattening of the cornea. There are three main corneal ring arc diameters, 140,160 , and $210^{\circ}$. The shorter the segment, the greater the astigmatic correction, the lesser the asphericity change. ${ }^{27}$ A new Ferrara intrastromal ring model has a short arc length of $140^{\circ}$ (140-ICRS) and has been recently used. The main advantage of this 140 arc length is its effect in astigmatism reduction. That is why, they have as a main indication, pellucid marginal degeneration, ${ }^{45}$ which leads to high astigmatism, besides corneal deformity. It has also been used in cases of astigmatic cones. These are central cones with high astigmatism and high keratometry.

We retrospectively reviewed the chart records of 65 consecutive patients implanted with Ferrara ICRS, which has a $140^{\circ}$ arch length (unpublished study). Patients included in the study presented with clear corneas and minimum corneal thickness of $300 \mu \mathrm{m}$ at the ring track. Patients were contact lens intolerant and/or showed progression of ectasia. The average follow-up was 16 months. The average age was $33.38( \pm 13.25), 54$ females $(80.6 \%)$ and 13 males (19.4\%).

The UDVA improved from 0.22 (decimal) preoperatively $( \pm 0.15)$ to 0.42 postoperatively $( \pm 0.42)(p<0.001)$. The CDVA improved from $0.38( \pm 0.20)$ to $0.59( \pm 0.21)$ $(\mathrm{p}<0.001)$. The mean minimum keratometry $(\mathrm{K} 1)$ did not change significantly; it reduced from $45.49( \pm 6.38)$ to $45.14( \pm 5.10)(p=0.354)$. The mean K2 decreased from 54.11 $( \pm 8.40)$ to $49.54( \pm 5.11)(\mathrm{p}<0.001)$. The average keratometry reduced from $49.87( \pm 7.018)$ to $47.34( \pm 4.90)(\mathrm{p}<0.001)$. The average asphericity changed from $-0.60( \pm 0.86)$ to -0.23 $( \pm 0.67)(p<0.001)$. The refractive astigmatism decreased from $-4.95( \pm 1.61)$ to $-2.55 \mathrm{D}( \pm 1.31)(\mathrm{p}<0.001)$. The mean preoperative astigmatism topography decreased from $-8.00( \pm 3.45)$ to $-4.53( \pm 2.52)(\mathrm{p}<0.001)$.

In selected cases of keratoconus with high astigmatism, the short arch segments (140 arch) seem to be more effective, in order to get a significant astigmatic reduction.

\section{THE 210 FERRARA ICRS}

The $210^{\circ}$ of arc Ferrara intrastromal ICRS have three major advantages over the conventional ICRS $\left(160^{\circ}\right)$ : (1) Minimal astigmatic induction; (2) corneal flattening, and (3) implantation of a single segment. These ICRS are especially useful for the nipple type of keratoconus. The 210-ICRS are an efficient method for keratoconus correction, significantly decreasing the keratometric values and spherical equivalent and improving UDVA and CDVA.

We retrospectively reviewed patient records of 80 eyes of 76 patients, which were consecutively operated, in which the 210 -ICRS were implanted. ${ }^{24}$ Statistical analysis included preoperative and postoperative UDVA, BCVA, spherical equivalent, and keratometry.

The mean follow-up time was 6.65 months. The mean UDVA increased from $20 / 350$ to $20 / 136\left(p^{\circ}={ }^{\circ} 0.001\right)$. The mean CDVA increased from $20 / 125$ to $20 / 55\left(\mathrm{p}^{\circ}={ }^{\circ} 0.0001\right.$ ). The mean preoperative spherical equivalent decreased from $-5.22 \mathrm{D}$, preoperative, to $-2.26 \mathrm{D}\left(\mathrm{p}^{\circ}={ }^{\circ} 0.050\right)$, postoperative.

Corneal tomography $\left(\right.$ Pentacam ${ }^{\circledR}$ ) showed corneal flattening in all eyes. The mean $\mathrm{K}_{1}$ decreased from $51.49 \mathrm{D}$ to $47.40 \mathrm{D}\left(\mathrm{p}^{\circ}={ }^{\circ} 0.00014\right)$, and the mean $\mathrm{K}_{2}$ decreased from $54.33 \mathrm{D}$ to $49.14 \mathrm{D}\left(\mathrm{p}^{\circ}={ }^{\circ} 0.00022\right)$. The mean keratometric astigmatism decreased from $3.65 \mathrm{D}$ (preoperative) to $2.69 \mathrm{D}$ (postoperative) $\left(\mathrm{p}^{\circ}={ }^{\circ} 0.0001\right)$.

\section{IMPLANTATION OF FERRARA ICRS IN POSTREFRACTIVE SURGERY CORNEAL ECTASIA}

We evaluated 25 eyes of 20 patients with corneal ectasia (13 males [15 eyes] and 7 females [10 eyes]) who underwent Ferrara intracorneal ICRS implantation. ${ }^{46}$

The mean follow-up time was $39.8^{\circ} \pm{ }^{\circ} 21.1$ months (Table 1). All patients had implanted only one segment of ICRS. A $160^{\circ}$ arc ICRS (160-ICRS) was implanted in 18 eyes, and the $210^{\circ}$ arc ICRS (210-ICRS) was implanted in 7 eyes.

The mean UDVA increased from 20/185 to 20/66 $(p=0.005)$. The mean CDVA increased from $20 / 125$ to $20 / 40(p=0.008)$ (Graph 1). The mean asphericity values 
decreased from -0.95 , preoperatively, to $-0.23(\mathrm{p}=0.006)$, postoperatively.

The mean pachymetry at the apex of the cornea increased from (mean) $457.7 \pm 48.7 \mu \mathrm{m}$ (361-542) to $466.2 \pm$ $49.8 \mu \mathrm{m}(381-559)(\mathrm{p}=0.025)$, and the pachymetry at the thinnest point of the cornea increased from $436.3 \pm 46.2 \mu \mathrm{m}$ $(348-533)$ to $453.9 \pm 49.3 \mu \mathrm{m}(370-548)(\mathrm{p}=0.000)$. A significant reduction in keratometric values was found at the last follow-up examination; mean preoperative keratometry was decreased from $45.41 \pm 5.63 \mathrm{D}$ (37.3-55.5) and changed significantly to $42.88 \pm 4.44 \mathrm{D}(31.2-54.1)(\mathrm{p}=0.000)$.

Our postoperative results show a significant improvement in UDVA and CDVA. Moreover, there was significant increase in corneal thickness. This can be explained by a theoretical cornea collagen remodeling induced by the implantation of ICRS.

We found a significant increase in asphericity values after the implantation of ICRS in this study. Interestingly, the mean postoperative value was -0.23 , which is considered the "normal" value for the general population. ${ }^{25,28-30,47}$ This value means that the normal physiologic asphericity of the cornea shows a significant individual variation ranging from mild oblate to moderate prolate. In an unpublished study, where we evaluated the corneal asphericity changes induced by the ICRS in keratoconus, we found that the Ferrara intrastromal ICRS implantation significantly increased the mean corneal asphericity from -0.85 to -0.32 . It is well known that most corneas after ablation laser procedures tend to become oblate, and when ectasia develops these corneas usually become prolate. However, the excess of prolatism usually found in keratoconus (primary) is usually of a much larger amount that that found in postrefractive surgery ectasia. The probable reason is that the $Q$ value after Ferrara ICRS becomes much closer to "normal" values than when the ICRS is used for keratoconus. As asphericity is one of the markers of visual quality, turning it "normal" can be a predictor of improvement of visual quality.

The keratometry values reduced significantly in all eyes. It can be realized that the mean preoperative values are usually lower than ones found in keratoconus (primary). This can be explained somewhat by the corneal flattening induced by the refractive procedure, usually in an optic zone of greater extent than the location of the ectasia.

Most of the implanted ICRS were 160-ICRS, the "conventional" ICRS. The remainder of eyes received the 210ICRS. The latter is usually reserved for central cones of nipple type. ${ }^{24}$ Some ectasia assume the same topographical pattern of nipple cones, in which we usually use the 210-ICRS with excellent results. These ICRS are reserved for cases with low astigmatism, in which we desire to flatten the cornea with minimal astigmatic induction.

The potential advantages of ICRS implantation over keratoplasty in eyes with post-LASIK ectasia are many. ${ }^{23,48}$ First, it avoids further laser treatment, eliminating central corneal wound healing. This leaves the optical center of the cornea untouched, enhancing the refractive outcome. Second, the technique is reversible in cases of an unsatisfactory refractive or clinical outcome, and minimal postoperative care is required. Third, adjustment can be performed using thinner or thicker ICRS. In cases of unexpected corneal shape changes, one segment can be removed or exchanged. ${ }^{49}$ Fourth, it avoids the complications of intraocular surgery.

These data are confirmed by several studies. ${ }^{9,50-52}$ Some long-term studies (ICRS in ectasia after LASIK) showed that ICRS yielded improvements in visual acuity, refractive status, and keratometric values without any progression in cases with post-LASIK corneal ectasia. ${ }^{53}$

\section{ENDOTHELIUM EVALUATION AFTER FERRARA ICRS IMPLANTATION}

We retrospectively reviewed patient records of 102 eyes of 81 patients, which were followed for a period of at least 1 year (mean follow-up: 45.7 months, standard deviation: 16.4 months; range: $13-71$ months). ${ }^{54}$ All patients had the diagnosis of keratoconus, post-LASIK ectasia, or pellucid degeneration. Statistical analysis included preoperative and postoperative keratometry and endothelial characteristics (cell count, average cell size, and coefficient of variation).

All patients completed at least 1 year of follow-up (13-71 months). Mean age was $30.5 \pm 8$ years. The mean cell count decreased from (mean \pm standard deviation [SD]) $2714 \pm 372$ to $2562 \pm 406$ cells $/ \mathrm{mm}^{2}$ ( $\mathrm{p}<0.001$ ). The calculated exponential cell loss rate over the mean interval of follow-up (4 years) was $1.4 \%$ per year. The average cell size increased from (mean \pm SD) $375 \pm 56$ to $-399 \pm 61 \mu^{2}$ $(p<0.001)$. The coefficient of variation increased from (mean $\pm S D) 0.22 \pm 0.075$ to $0.26 \pm 0.010(p=0.001)$.

The mean maximum cell size increased from (mean \pm SD) $529 \pm 116$ to $639 \pm 225 \mu^{2}(\mathrm{p}<0.001)$. The mean minimum cell size varied from (mean \pm SD) $225 \pm 36$ to $226 \pm 54 \mu^{2}$ $(\mathrm{p}=0.936)$.

There was significant corneal flattening as shown by keratometry changes. The mean $\mathrm{K}$ decreased from $47.70 \pm 2.29(43.70-53.80)$ to $44.86 \pm 2.02(41.20-51.20)$ $(\mathrm{p}=0.0001)$.

In our study, we found a 1.4\% loss of endothelial cells per year. Considering that most of the studied patients were young, the rate of endothelial cell loss was slightly higher than in normal eyes (1.1\%). ${ }^{55,56}$ Moreover, there is no study in the current literature that shows the profile of the "normal" endothelial loss in keratoconus corneas, which could be higher than in normal corneas. The only report in the literature regarding the endothelium profile of keratoconus is nonprospective and studied only 12 eyes. ${ }^{57}$ 
Endothelial cell loss after PKP is known to be an ongoing process even years after surgery. It is well known that the cell loss is higher than in the early time course after surgery and decreases 3 to 5 years after surgery. There is a great variation of rates of cell loss after PKP, ranging from $4.2^{30}$ to $9.4 \%$ per year, at the long-term follow-up. ${ }^{58-60}$ Even after deep anterior lamellar keratoplasty (DALK), which is a surgical technique that spares the receptor endothelium, cell loss has been reported. In one study, a decrease in average preoperative endothelial cell count of approximately 200 cells $/ \mathrm{mm}^{2}$ was observed during the first 12 months of surgery. ${ }^{61,62}$

The only study that assessed the endothelial after intrastromal ICRS (Intacs, Addition Technology Inc.) implantation reported that after 24 months of surgery, all corneal regions had a slight decrease in cell density. ${ }^{63}$ In all eyes, mean central and peripheral endothelial cell counts remained above 2,495 cells $/ \mathrm{mm}^{2}$. Our results are similar, we obtained a higher average postoperative cell count $\left(2,562\right.$ cells $\left./ \mathrm{mm}^{2}\right)$, and we had a longer follow-up (4 years).

Wollensak et al, ${ }^{64}$ in a collagen cross-linking study in keratoconus, showed that the corneal transparency and the endothelial cell density $(p=0.45)$ remained unchanged. The follow-up was 23 months, and the sample was only 23 eyes. The same author, in an experimental study in rabbits, ${ }^{23}$ showed that riboflavin-ultraviolet $\mathrm{A}$ (UVA) treatment should be safe as long as the dose is less than the endothelial cytotoxic dose of $0.65 \mathrm{~J} / \mathrm{cm}^{2}$. In human corneas, the endothelial cytotoxic UVA dose is reached in corneas thinner than $400 \mu$, which is not uncommon in keratoconus patients. Moreover, the data obtained from normal corneas of rabbit cannot be extrapolated to human keratoconic corneas, which can have a different metabolism and response to cross-linking. The study has a limitation of measure the endothelial toxicity only at 4 and 24 hours after treatment. The long-term endothelial cytotoxicity was not evaluated by the study.

Our study suggests that some endothelial changes occur after Ferrara ICRS implantation. However, these changes are minimal and nonclinically significant, since the endothelial cell loss rate is not much higher than that normally expected for normal corneas. In contrast, the long-term endothelial cell loss after other therapies for keratoconus is much higher (as in PKP, or even DALK, in which the receptor endothelium is spared) or unknown (as in cross-linking).

\section{CONTACT LENS FITTING AFTER FERRARA ICRS IMPLANTATION}

Contact lens fitting in keratoconus patients can be considerably facilitated after Ferrara ICRS implantation. Once there is corneal surface regularization with reduction of the excess of prolatism, the majority of patients can be well fitted with contact lens after the surgery.

The contact lens trial must be done after 3 months of surgery, which is the period required for keratometry and refraction stabilization. It is very common that patients that usually were intolerant to rigid gas-permeable contact lens in the preoperative period become tolerant after the surgery. It is frequently possible to fit soft contact lenses in these patients. Moreover, there is a very good stability of the contact lenses after the surgery, with "losses of lenses" caused by instability (a common complaint before the surgery) not occurring anymore.

There are a few studies about contact lens fitting after ICRS implantation. One study evaluated the fitting of a lathed soft toric contact lens (STCL) after the implant of ICRS to treat keratoconus. It was found that STCL fitting was successful in $75,66.66$, and $0 \%$ of the ICRS implanted eyes with stages I-III keratoconus respectively. SpectacleCDVA was 1.5 lines better, and mean corneal power was 3.62 D lower in the successful STCL group. Piggy-back $(\mathrm{PB})$ refitting achieved a $\mathrm{PB}-\mathrm{CDVA} \leq 0.2 \log \mathrm{MAR}$ in all cases. A similar difference in the CDVA change achieved by contact lenses $v$ s spectacles was observed in the successful STCL and PB refitted groups. They concluded that STCL fitting is a feasible option in a large proportion of patients implanted with ICRS. When these lenses are unsatisfactory, a PB system is a good alternative. ${ }^{65}$

Scleral contact lenses $(\mathrm{ScCl})$ are used for improving vision in patients with high or irregular astigmatism, such as keratoconus, pellucid marginal degeneration, keratoglobus, and post-keratoplasty astigmatism (Fig. 1). ${ }^{66}$ Scleral lenses are lenses with bearing only on the sclera with diameter of the lens being $15 \mathrm{~mm}$ and above. Miniscleral lenses have diameters between 15 and $18 \mathrm{~mm}$, and true scleral lenses have $18 \mathrm{~mm}$ diameter (more than $6 \mathrm{~mm}$ bearing on sclera). Mini-scleral lenses have less corneal clearance as compared with true sclerals. They were

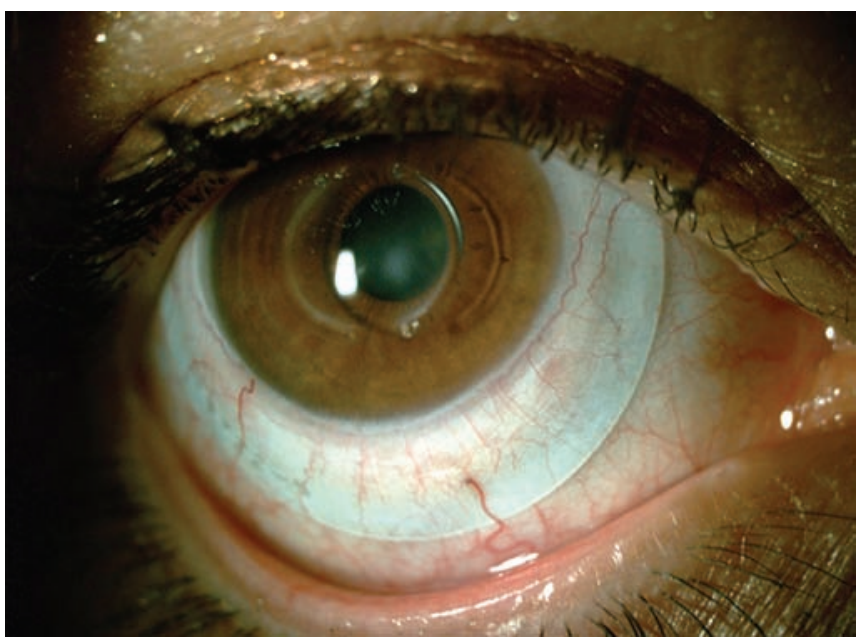

Fig. 1: Scleral contact lens in a patient implanted with Ferrara ICRS 
used for a long time and then abandoned. Recently, after significant improvement in its manufacturing process, it has been used with great success in keratoconus patients with or without previous ICRS implantation.

High cost and the special training required in assessing the fitting and then modifying the design is quite challenging. Still, with the advances in technology, the field of $\mathrm{ScCl}$ has led to its resurgence as specialized lenses. Despite these challenges, improvement in visual acuity with scleral lenses is significant and worth its fitting. ${ }^{66}$

\section{SURGICAL CORRECTION OF RESIDUAL AMETROPIA AFTER FERRARA ICRS IMPLANTATION}

Keratoconus patients frequently have high myopia. Although the corneal shape in these eyes may improve after ICRS implantation, most patients require contact lenses or spectacles to correct the residual refractive error. Some studies ${ }^{67-69}$ found that implantation of a phakic intraocular lens (pIOL) was a safe, effective, and predictable way to correct myopia associated with keratoconus (Figs 2A and B).

The success of the sequential procedure (ICRS followed by $\mathrm{pIOL}$ ) requires knowledge of when the refraction is stable after ICRS insertion and whether the progression of keratoconus is halted because keratoconus progression leading to a refractive change can be a problem after $\mathrm{pIOL}$ implantation. A previous study ${ }^{18}$ evaluated the long-term results and stability of ICRS implantation for keratoconus correction. The authors found that CDVA stability was achieved, with no significant differences in refraction from 6 to 36 months after ICRS implantation; there was also an improvement in corneal topography. However, there was a significant increase in $\mathrm{K}$ values over time. It has been a consensus that pIOL should be implanted at least 6 months after ICRS implantation.

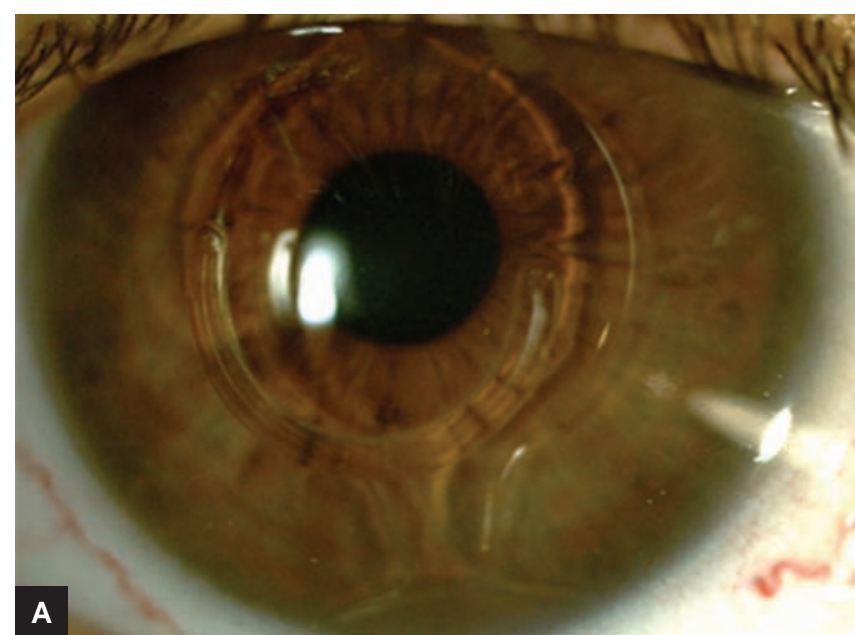

\section{FERRARA ICRS IMPLANTATION FOR CORRECTION OF IRREGULAR ASTIGMATISM AFTER KERATOPLASTY}

After keratoplasty, postoperative astigmatism is a common condition in clinical practice. Some studies ${ }^{32,70}$ have investigated the use of ICRS as an alternative surgical option for the treatment of astigmatism in patients who underwent keratoplasty for keratoconus (Figs 3A and B).

One of these studies ${ }^{70}$ found that the mean CDVA (LogMAR) improved from $0.45 \pm 0.17$ (0.18-1.00) to $0.30 \pm 0.17(0.00-1.00)$. The mean preoperative standard error was $-6.34 \pm 3.40 \mathrm{D}(0.37$ to $-16.50 \mathrm{D})$ and $-2.66 \pm 2.52 \mathrm{D}$ $(0.87$ to $-10.50 \mathrm{D})$ postoperatively. The mean spherical refractive error reduced from $-7.10 \pm 3.07 \mathrm{D}(2.15-16.68 \mathrm{D})$ preoperatively to $-3.46 \pm 2.05 \mathrm{D}(0.88-10.79 \mathrm{D})$ postoperatively. No patient lost visual acuity. The mean corneal topographic astigmatism decreased from $3.37 \pm 1.51 \mathrm{D}$ preoperatively to $1.69 \pm 1.04 \mathrm{D}$ postoperatively. The mean maximum $\mathrm{K}$ value decreased from $48.09 \pm 2.56$ to $44.17 \pm 2.67 \mathrm{D}$, and the mean minimum $\mathrm{K}$ value decreased from $44.90 \pm 2.54$ to $42.46 \pm 2.63 \mathrm{D}$. All changes were statistically significant $(\mathrm{p}<0.0001)$.

There are several potential advantages of ICRS implantation over other surgical techniques in eyes with high astigmatism after PKP. First, ICRS implantation avoids any excimer laser treatment, eliminating central corneal wound healing, which could be unsatisfactory in post-PKP corneas. This leaves the optical center of the cornea untouched, enhancing refractive outcomes. Second, the technique is reversible in cases of an unsatisfactory refractive or clinical outcome. Third, adjustment can be performed using thinner or thicker rings. In cases of unexpected corneal shape changes, one segment can be removed or exchanged. Fourth, it avoids the complications of intraocular surgery.

The results of these studies suggested that ICRS seem to be a promising treatment for astigmatism after keratoplasty, especially in those with thin and irregular corneas.

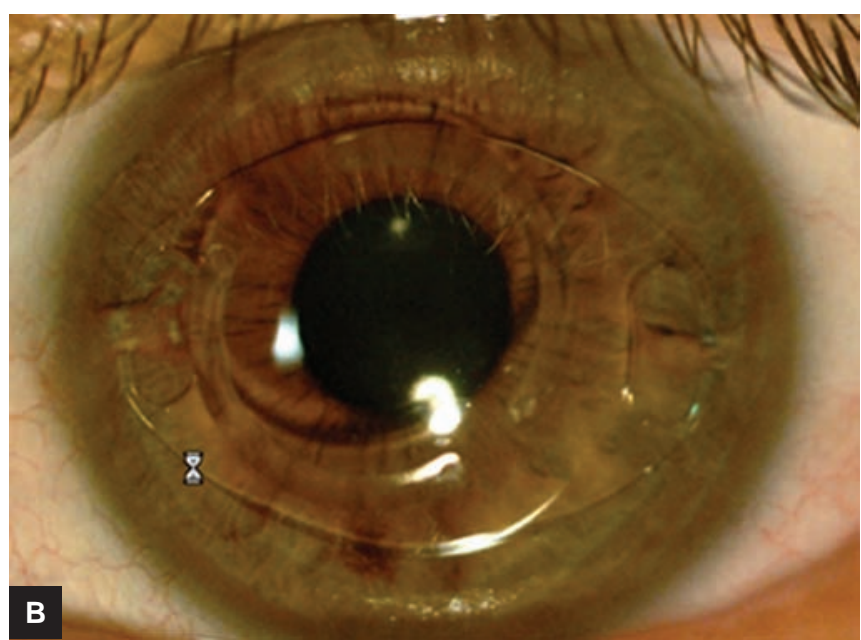

Figs 2A and B: Phakic intraocular lens in patients implanted with Ferrara ICRS 

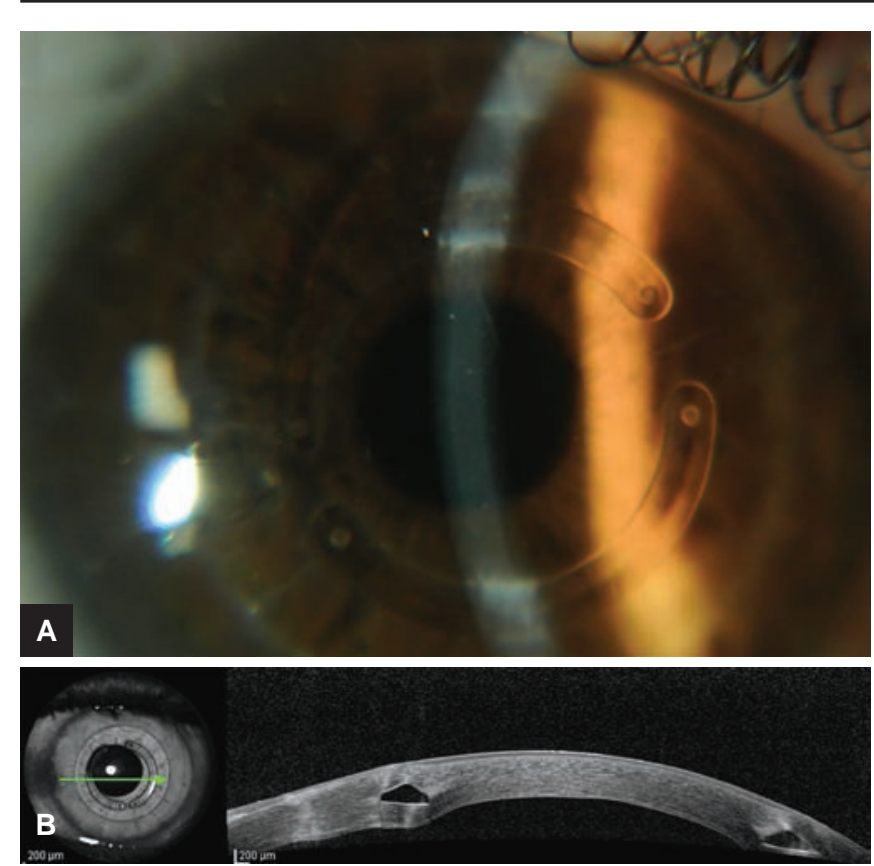

Figs $3 A$ and B: Ferrara ICRS implantation in a patient with corneal graft

\section{ABERROMETRY AFTER FERRARA ICRS IMPLANTATION}

The wavefront corneal changes induced by the implantation of the Ferrara ICRS have been evaluated by several studies. ${ }^{33,70}$ The decrease of vision in patients with keratoconus is caused not only by sphero-cylindrical refractive errors (low-order aberrations), but also to a significant extent by high-order ones. This is clearly explained by the fact that spectacles in most cases are not able to provide full correction. The predominant defect is in the coma aberration, specifically its vertical component.

The studies describe a statistically significant reduction of all evaluated aberrations, not only the reduction of wavefront aberrations, but also the prediction of possible surgical-induced aberrations. These data (reduction and induction of aberrations) could be considered in a nomogram to assist in the ring (or pair of rings) selection for the best visual quality results.

\section{FERRARA ICRS $\times$ KERATOPLASTY}

Barbara and Barbara ${ }^{71}$ have published the only paper that compares the clinical outcomes between ICRS implantation and keratoplasty in keratoconus patients. They found better UDVA and CDVA in the ICRS group of patients; the PKP group has more myopia and astigmatism but lower keratometry readings; all these differences were not statistically significant. intrastromal corneal ring segments implantation has been shown to be a less invasive procedure with less postoperative complications than PKP.

\section{COMPLICATIONS}

The incidence of complications after the learning curve is very low. ${ }^{72}$ Postoperative complications can be related to (1) The surgical technique, (2) the nomogram, and (3) the ICRS itself. The complications related to the surgical technique are as follows: Extrusion (due to a shallow tunnel), infection, bad centration of the segment (wrong placement of the ICRS), migration, and misplacement or asymmetry of the segments.

The complications related to the nomogram are linked to the corneal biomechanics and can be (1) Overcorrection and (2) undercorrection. Although the predictability of postoperative results is high, in some cases, overcorrection and undercorrection can occur due to viscoelastic and biomechanic profile of the different keratoconic corneas.

The complications related to the ICRS itself are as follows: (1) Halos and glare, (2) periannular deposits, and (3) neovascularization. Halos are reported by $10 \%$ of patients and can be related to the pupil size. This symptom tends to fade or at least diminish over time. In very symptomatic cases, we usually prescribe pilocarpine or brimonidine tartarate at night, to constrict the pupil and alleviate the undesired reflexes. The periannular opacities are small white debris lying along the ICRS internal face (Fig. 4). They do not tend to grow and do not harm visual performance, being only antiesthetical when submitted to biomicroscopic examination. Neovascularization of the stromal tunnel is rare and usually occurs in atopic patients (Fig. 5). Subconjunctival bevacizumab has shown to be an effective option to treat neovascularization of the tunnel. ${ }^{73,74}$

Coskunseven et $\mathrm{al}^{38}$ reported the complication rate after implantation of ICRS assisted by the femtosecond laser in 850 keratoconus eyes. They found an incidence of $2.7 \%$ of incomplete channel formation and $0.6 \%$ of endothelial

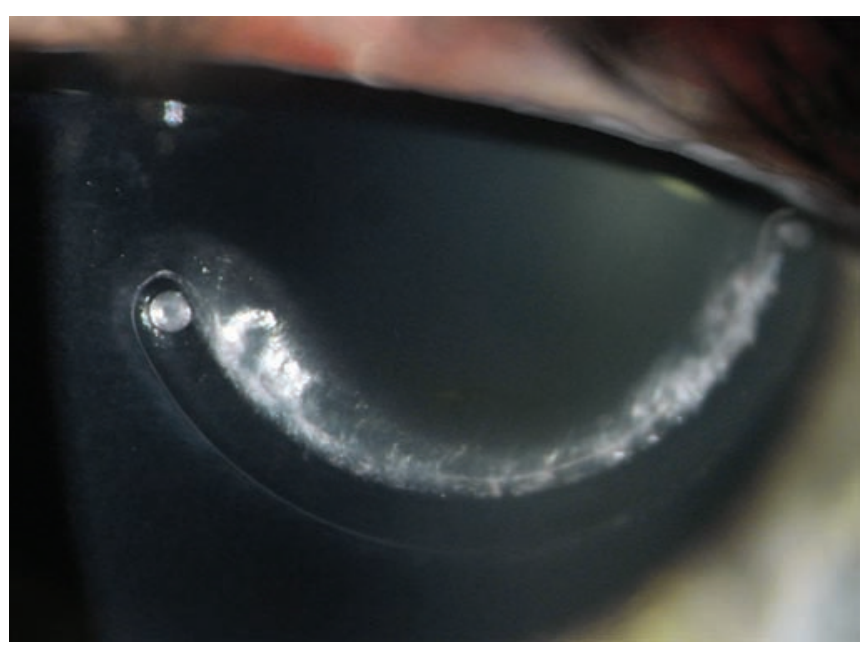

Fig. 4: White deposits in a patient implanted with Ferrara ICRS 


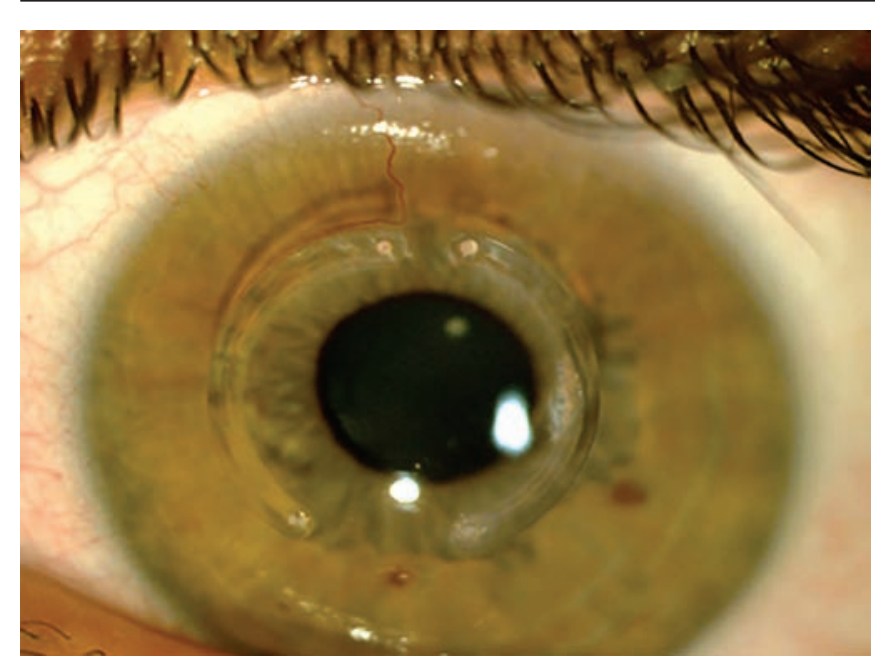

Fig. 5: Neovascularization of the tunnel in a patient implanted with Ferrara ICRS

perforation. About postoperative complications, there were $1.3 \%$ cases of segment migration, $0.2 \%$ of corneal melting, and $0.1 \%$ case of mild infection. The overall complication rate was $5.7 \%$ (49 cases out of 850 eyes).

Kwitko and Severo ${ }^{41}$ reported ICRS decentration in $3.9 \%$ of cases, segment extrusion in $19.6 \%$, and bacterial keratitis in $1.9 \%$. As the author mentioned in his paper, the surgeon's learning curve and different healing processes in keratoconic corneas can cause the majority of complications related to the surgical technique. Once the surgical procedure is mastered, the complication rate related to the surgery itself is very low. The surgical steps must be followed carefully (the stromal tunnel must be constructed with the adjustable diamond knife set at $80 \%$ of local corneal thickness to reduce the chance of a shallow tunnel and subsequent ICRS extrusion) to avoid surgery-related complications.

As a general rule, it must be assumed that the thickest segment of a pair of segments cannot exceed half thickness of the cornea in its bed. If this happens, a pair of segments that fit this condition has to be chosen even if the achieved correction is smaller than the desired one.

The majority of the complications can be managed by ICRS exchange, reposition, addition, or removal. One study ${ }^{49}$ evaluated the visual, refractive, and topographic changes occurring after reoperation in keratoconic eyes. In this study, the incidence of patients requiring follow-up surgery due to the overcorrection or undercorrection was $3.4 \%$. For these patients, there was improvement of UDVA, CDVA, keratometry, and pachymetry. However, asphericity and spherical equivalent did not improve in these patients undergoing subsequent surgery, perhaps due to the scarring of corneal tissue and/or stroma secondary to the first procedure. The mean follow-up time after the reoperation was $30.5 \pm 9.7$ months. Uncorrected distance visual acuity improved from $20 / 300$ to $20 / 80$ ( $p=0.005)$; CDVA improved from $20 / 160$ to $20 / 50(p=0.0002)$, the mean keratometry reduced from $49.33 \pm 4.19 \mathrm{D}$ to $46.16 \pm 3.90 \mathrm{D}(\mathrm{p}=0.0001)$, and the mean pachymetry at the thinnest point increased from $450 \pm 42.9$ to $469 \pm 40.8 \mu \mathrm{m}$ $(\mathrm{p}=0.0001)$.

Good outcomes can be obtained even after removal, addition, reposition, or exchange of ICRS. Ferrara ICRS implantation has been shown to be a reversible and readjustable surgical procedure for keratoconus treatment.

\section{COMMENTS}

Preliminary investigations have demonstrated that intracorneal ICRS are effective in the treatment of astigmatism and myopia with astigmatism, ${ }^{9}$ with preservation of CDVA and stable results over time. ${ }^{10}$ The objective of the addictive technology is to reinforce the cornea, decrease the corneal irregularity, and provide an improvement of the visual acuity in affected patients.

It is important to note an important reduction of keratometric values after the Ferrara ICRS implantation, with corneal regularization and return to its physiological values when the intervention is made early in the course of the disease. ${ }^{75,76}$ However, in a late intervention, with values of keratometry superior to $56 \mathrm{D}$, a reduction of the $\mathrm{K}$ is also shown, high keratometry values remain when compared with a normal corneal keratometry. ${ }^{77}$

Ferrara's ICRS technique has the objective of reshaping the abnormal cornea, flattening the periphery, and decreasing the corneal astigmatism. With the objective to avoid, or at least postpone $\mathrm{e}^{2,17-19,39}$ the keratoplasty, the technique is within the options of visual rehabilitation of patients with keratoconus.

Observing the clinical outcomes of our patients, we could realize that the visual rehabilitation curve and refractive stabilization occurs on average after 3 months of surgery. The visual rehabilitation process follows a certain pattern. In general, vision improvement is quick and on the day following surgery, the patients usually report subjective and objective improvement of the visual acuity. However, it usually reverts within the first weeks, and at the end of the first month, the patient reports his/her vision was better immediately after surgery. The same fluctuation is detected in relation to refraction and keratometry. From the first month on, the vision starts to improve and refractive and keratometric fluctuation decreases. From the third month on, it stabilizes. Then, it is possible to correct the residual ametropia, if necessary, by means of eyeglasses, rigid or soft contact lenses, or even implanting plOL for high myopia correction.

We could notice that patients having central cones show a longer rehabilitation time, ${ }^{24}$ which means that the central flattening is slower, while patients with decentralized cones have faster rehabilitation. ${ }^{39}$ We believe that this is due to the dislocation or the corneal apex toward 
its physiological position in front of the pupil. In some cases, we could observe that after ICRS implantation, there was an increase in myopia and in the keratometric readings, caused by this same phenomenon.

Symptoms, such as photophobia, visual discomfort, eye strain, and itching reduce or disappear after surgery. Most of the keratoconus patients are allergic; therefore, we recommend strongly that they should not rub their eyes, which could displace the segments, and stimulate the disease progression. In addition, rubbing could theoretically change the regularity of the corneal surface leading to visual acuity loss. In some cases, it is necessary to use eye shields at night to prevent the patient from rubbing the eyes compulsively and unwarily.

The satisfaction level is high. We could observe that the fear of becoming blind in those patients, along with the fearsome possibility of a transplant in case of a continuously evolving condition, is very common. The possibility of postponing those eventualities generates great relief in the patients. Our cases show that, besides correcting the corneal deformity, the cone evolution is interrupted. Along with this interruption, we could also observe a decrease in corneal opacity and the other symptoms aforementioned.

The surgery is simple and well reproducible, although it is not an easy procedure. As in any other procedure, it must be well executed to attain a consistent result.

The incidence of complications is very low, around 3 to $5 \%$, compatible with the levels required for refractive procedures. It should be emphasized that the corneal ICRS implant is essentially an orthopedic technique designed to enable the correction of a structural deformity. As an advantage, it provides simultaneous refractive correction, although not well predictable, as with other refractive procedures.

Whenever it was necessary to perform keratoplasty, the ICRS not only helped the procedure, but also provided a better centralization during trephination.

We could also notice that, after surgery, there was a decrease in the corneal sensitivity, resulting in greater comfort in contact lens fitting, which was not possible before the operation.

The incidence of complications is greater in more advanced stages, because the cornea is thinner, and the pressure generated inside the stroma after the ICRS implantation can cause the displacement of segments toward the incisions, eventually extruding the segments.

\section{CONCLUSION}

From the results obtained, we can state that this therapeutic approach has the following benefits:

- Low morbidity, because it preserves the corneal structure and has a low rate of complications, ${ }^{38,39}$ allowing $95 \%$ of the operated patients to quickly reintegrate themselves to their everyday activities.
- Reversibility, because it enables the cornea to revert to the preoperative dimensions when the segments are removed. ${ }^{49}$

- Readjustability through segment replacement. In some cases, it was possible to correct hypercorrection removing just one of the segments. ${ }^{49}$

- Lack of rejection - the acrylic which the ICRS is made of is inert and biocompatible.

- Patients' high satisfaction rate.

- As an orthopedic technique, it corrects corneal deformity and restores the physiologic curvature. After the surgery it is possible to correct the residual ametropia with conventional optical correction or contact lenses. ${ }^{65}$

- Stabilization or delay of cone progression. ${ }^{19}$

- Lack of a minimum age for surgery, thus making it possible to reduce the waitlists for transplants in eye banks (30\% of the transplants in eye banks are attributed to keratoconus).

- Possibility of association with other procedures like contact lens fitting and intraocular lenses.

- No interference whatsoever with corneal transplant.

\section{REFERENCES}

1. Colin J, Velou S. Implantation of Intacs and a refractive intraocular lens to correct keratoconus. J Cataract Refract Surg 2003 Apr;29(4):832-834.

2. Kymionis GD, Siganos CS, Tsiklis NS, Anastasakis A, YooSH, Pallikaris AI, Astyrakakis N, Pallikaris IG. Long-term follow-up of Intacs in keratoconus. Am J Ophthalmol 2007 Feb;143(2):236-244.

3. Colin J, Cochener B, Savary G, Malet F. Correcting keratoconus with intracorneal rings. J Cataract Refract Surg 2000 Aug;26(8):1117-1122.

4. Colin J, Cochener B, Savary G, Malet F, Holmes-Higgin D. INTACS inserts for treating keratoconus: one-year results. Ophthalmology 2001 Aug;108(8):1409-1414.

5. Siganos CS, Kymionis GD, Kartakis N, Theodorakis MA, Astyrakakis N, Pallikaris IG. Management of keratoconus with Intacs. Am J Ophthalmol 2003 Jan;135(1):64-70.

6. Siganos D, Ferrara P, Chatzinikolas K, Bessis N, Papastergiou G. Ferrara intrastromal corneal rings for the correction of keratoconus. J Cataract Refract Surg 2002 Nov;28(11):1947-1951.

7. Beniz LA, Queiroz GH, Queiroz CF, Lopes WL, Moraes LF, Beniz J. Intrastromal corneal ring segments delay corneal grafting in patients with keratoconus. Arq Bras Oftalmol 2016 Feb;79(1):30-32.

8. Miranda D, Ferrara P. Ferrara intrastromal corneal ring segments for severe keratoconus. J Refract Surg 2003 Nov-Dec; 19(6):645-653.

9. Brenner LF, Alió JL, Vega-Estrada A, Baviera J, Beltrán J, CoboSoriano R. Indications for intrastromal corneal ring segments in ectasia after laser in situ keratomileusis. J Cataract Refract Surg 2012 Dec;38(12):2117-2124.

10. Suiter BG, Twa MD, Ruckhofer J, Schanzlin DJ. A comparison of visual acuity, predictability, and visual function outcomes after intracorneal ring segments and laser in situ keratomileusis. Trans Am Ophthalmol Soc 2000;98:51-55; discussion 55-57. 
11. Baïkoff G, Maia N, Poulhalec D, Fontaine A, Giusiano B. Diurnal variations in keratometry and refraction with intracorneal ring segments. J Cataract Refract Surg 1999 Aug;25(8): 1056-1061.

12. Ruckhofer J, Stoiber J, Twa MD, Grabner G. Correction of astigmatism with short arc-length intrastromal corneal ring segments: preliminary results. Ophthalmology 2003 Mar;110(3):516-524.

13. Ruckhofer J, Stoiber J, Alzner E, Grabner G. One year results of European multicenter study of intrastromal corneal ring segments. Part 2: complications, visual symptoms, and patient satisfaction. J Cataract Refract Surg 2001 Feb;27(2):287-296.

14. Nosé W, Neves RA, Burris TE, Schanzlin DJ, Belfort Júnior R. Intrastromal corneal ring: 12-month sighted myopic eyes. J Refract Surg 1996 Jan-Feb;12(1):20-28.

15. Burris TE, Ayer CT, Evensen DA, Davenport JM. Effects of intrastromal corneal ring size and thickness on corneal flattening in human eyes. Refract Surg 1991 Jan-Feb;7(1):46-50.

16. Zare MA, Hashemi $H$, Salari MR. Intracorneal ring segment implantation for the management of keratoconus: safety and efficacy. J Cataract Refract Surg 2007 Nov;33(11):1886-1891.

17. Torquetti L, Berbel RF, Ferrara P. Long-term follow-up of intrastromal corneal ring segments in keratoconus. J Cataract Refract Surg 2009 Oct;35(10):1768-1773.

18. Alió JL, Shabayek MH, Artola A. Intracorneal ring segments for keratoconus correction: long-term follow-up. J Cataract Refract Surg 2006 Jun;32(6):978-985

19. Torquetti L, Ferrara G, Almeida F, Cunha L, Araujo LP, Machado A, Marcelo Lyra J, Merayo-Lloves J, Ferrara P. Intrastromal corneal ring segments implantation in patients with keratoconus: 10-year follow-up. J Refract Surg 2014 Jan;30(1):22-26.

20. Barbara A, Barbara R. Long-term follow-up of Ferrara rings segments for the treatment of keratoconus. Int J Keratoconus Ectatic Corneal Dis 2013 Jan-Apr;2(1):34-39.

21. Holmes-Higgin DK, Burris TE. Corneal surface topography and associated visual performance with INTACS for myopia: phase III clinical trial results. The INTACS Study Group. Ophthalmology 2000 Nov;107(11):2061-2071.

22. Rabinowitz YS. Keratoconus. Surv Ophthalmol 1998 Jan-Feb; 42(4):297-319.

23. Rodríguez LA, Guillén PB, Benavides MA, Garcia L, Porras D, Daqui-Garay RM. Penetrating keratoplasty versus intrastromal corneal ring segments to correct bilateral corneal ectasia: preliminary study. J Cataract Refract Surg 2007 Mar;33(3):488-496.

24. Ferrara P, Torquetti L. Clinical outcomes after implantation of a new intrastromal corneal ring with a 210-degree arc length. J Cataract Refract Surg 2009 Sep;35(9):1604-1608.

25. Bottos KM, Leite MT, Aventura-Isidro M, Bernabe-Ko J, Wongpitoonpiya N, Ong-Camara NH, Purcell TL, Schanzlin DJ. Corneal asphericity and spherical aberration after refractive surgery. J Cataract Refract Surg 2011 Jun;37(6):1109-1115.

26. Koller T, Iseli HP, Hafezi F, Mrochen M, Seiler T. Q-factor customized ablation profile for the correction of myopic astigmatism. J Cataract Refract Surg 2006 Apr;32(4):584-589.

27. Torquetti L, Ferrara P. Corneal asphericity changes after implantation of intrastromal corneal ring segments in keratoconus. J Emmetropia 2010;1:178-181.

28. Yebra-PimentelE,Gonzalez-JeijomeJM,Cervino A,GiraldezMJ, Gonzalez-Perez J, Parafita MA. Corneal asphericity in a young adult population. Clinical implications. Arch Soc Esp Oftalmol 2004 Aug;79(8):385-392.
29. Calossi A. Corneal asphericity and spherical aberration. J Refract Surg 2007 May;23(5):505-514.

30. Sheridan M, Douthwaite WA. Corneal asphericity and refractive error. Ophthalmic Physiol Opt 1989 Jul;9(3):235-238.

31. Kubaloglu A, Sari ES, Cinar Y, Cingu K, Koytak A, Coşkun E, Ozertürk Y. Comparison of mechanical and femtosecond laser tunnel creation for intrastromal corneal ring segment implantation in keratoconus: prospective randomized clinical trial. J Cataract Refract Surg 2010 Sep;36(9):1556-1561.

32. Lisa C, García-Fernández M, Madrid-Costa D, Torquetti L, Merayo-Lloves J, Alfonso JF. Femtosecond laser-assisted intrastromal corneal ring segment implantation for high astigmatism correction after penetrating keratoplasty. J Cataract Refract Surg 2013 Nov;39(11):1660-1667.

33. Piñero DP, Alio JL, El Kady B, Coskunseven E, Morbelli H, Uceda-Montanes A, Maldonado MJ, Cuevas D, Pascual I. Refractive and aberrometric outcomes of intracorneal ring segments for keratoconus: mechanical versus femtosecondassisted procedures. Ophthalmology 2009 Sep;116(9):1675-1687.

34. Coskunseven E, Kymionis GD, Bouzoukis DI, Aslan E, Pallikaris I. Single intrastromal corneal ring segment implantation using the femtosecond laser after radial keratotomy in a keratoconic patient. J Cataract Refract Surg 2009 Jan;35(1):197-199.

35. Yeung SN, Ku JYF, Lichtinger A, Low SAW, Kim P, Rootman DS. Efficacy of single or paired intrastromal corneal ring segment implantation combined with collagen crosslinking in keratoconus. J Cataract Refract Surg 2013 Aug;39(8):1146-1151.

36. Pinero DP, Alio JL, El Kady B, Pascual I. Corneal aberrometric and refractive performance of 2 intrastromal corneal ring segment models in early and moderate ectatic disease. J Cataract Refract Surg 2010 Jan;36(1):102-109.

37. Shabayek MH, Alió JL. Intrastromal corneal ring segment implantation by femtosecond laser for keratoconus correction. Ophthalmology 2007 Sep;114(9):1643-1652.

38. Coskunseven E, Kymionis GD, Tsiklis NS, Atun S, Arslan E, Siganos CS, Jankov M, Pallikaris IG. Complications of intrastromal corneal ring segment implantation using a femtosecond laser for channel creation: a survey of 850 eyes with keratoconus. Acta Ophthalmol 2011 Feb;89(1):54-57.

39. Ferrara G, Torquetti L, Ferrara P, Merayo-Lloves J. Intrastromal corneal ring segments: visual outcomes from a large case series. Clin Exp Ophthalmol 2012 Jul;40(5):433-439.

40. Coskunseven E, Kymionis GD, Talu H, Aslan E, Diakonis VF, Bouzoukis DI, Pallikaris I. Intrastromal corneal ring segment implantation with the femtosecond laser in a postkeratoplasty patient with recurrent keratoconus. J Cataract Refract Surg 2007 Oct;33(10):1808-1810.

41. Kwitko S, Severo NS. Ferrara intracorneal ring segments for keratoconus. J Cataract Refract Surg 2004 Apr;30(4):812-820.

42. Rabinowitz YS, Li X, Ignacio TS, Maguen E. INTACS inserts using the femtosecond laser compared to the mechanical spreader in the treatment of keratoconus. J Refract Surg 2006 Oct;22(8):764-771.

43. Kouassi F-X, Buestel C, Raman B, Melinte D, Touboul D, Gallois A, Colin J. Comparison of the depth predictability of intra corneal ring segment implantation by mechanical versus femtosecond laser-assisted techniques using optical coherence tomography (OCT Visante ${ }^{\circledR}$ ). J Fr Ophtalmol 2012 Feb;35(2):94-99.

44. Pesando PM, Ghiringhello MP, Di Meglio G, Romeo S. Treatment of keratoconus with Ferrara ICRS and consideration of the efficacy of the Ferrara nomogram in a 5-year follow-up. Eur J Ophthalmol 2010 Sep-Oct;20(5):865-873. 
45. Rodriguez-Prats J, Galal A, Garcia-Lledo M, De La Hoz F, Alió JL. Intracorneal rings for the correction of pellucid marginal degeneration. J Cataract Refract Surg 2003 Jul;29(7): 1421-1424.

46. Torquetti L, Ferrara P. Intrastromal corneal ring segment implantation for ectasia after refractive surgery. J Cataract Refract Surg 2010 Jun;36(6):986-990.

47. Gonzalez-Meijome JM, Villa-Collar C, Montés-Micó R, Gomes A. Asphericity of the anterior human cornea with different corneal diameters. J Cataract Refract Surg 2007 Mar;33(3): 465-473.

48. Ozertürk Y, Sari ES, Kubaloglu A, Koytak A, Piñero D, AkyolS. Comparison of deep anterior lamellar keratoplasty and intrastromal corneal ring segment implantation in advanced keratoconus. J Cataract Refract Surg 2012 Feb;38(2):324-332.

49. Torquetti L, Ferrara G, Almeida F, Cunha L, Ferrara P, MerayoLloves J. Clinical outcomes after intrastromal corneal ring segments reoperation in keratoconus patients. Int J Ophthalmol 2013 Dec;6(6):796-800.

50. Stival LR, Nassaralla BR, Figueiredo MN, Bicalho F, Nassaralla JJ Jr. Intrastromal corneal ring segment implantation for ectasia after refractive surgery. Arq Bras Oftalmol 2015 Jul-Aug;78(4):212-215.

51. Tunc Z, Helvacioglu F, Sencan S. Evaluation of intrastromal corneal ring segments for treatment of post-LASIK ectasia patients with a mechanical implantation technique. Indian J Ophthalmol 2011 Nov-Dec;59(6):437-443.

52. Piñero DP, Alio JL, Uceda-Montanes A, El Kady B, Pascual I. Intracorneal ring segment implantation in corneas with postlaser in situ keratomileusis keratectasia. Ophthalmology 2009 Sep;116(9):1665-1674.

53. Yildirim A, Cakir H, Kara N, Uslu H. Long-term outcomes of intrastromal corneal ring segment implantation for postLASIK ectasia. Cont Lens Anterior Eye 2014 Dec;37(6):469-472.

54. Ferrara P, Torquetti L. Corneal endothelial profile after Ferrara Ring implantation. J Emmetropia 2010;1:29-32.

55. Patel SV, McLaren JW, Bachman LA, Bourne WM. Comparison of flex-center, center, and corner methods of corneal endothelial cell analysis. Cornea 2010 Sep;29(9):1042-1047.

56. Higa A, Sakai H, Sawaguchi S, Iwase A, Tomidokoro A, Amano S, Araie M. Corneal endothelial cell density and associated factors in a population-based study in Japan: the Kumejima study. Am J Ophthalmol 2010 May;149(5):794-799.

57. Laing RA, Sandstrom MM, Berrospi AR, Leibowitz HM. The human corneal endothelium in keratoconus: a specular microscopic study. Arch Ophthalmol 1979 Oct;97(10):1867-1869.

58. Regis-Pacheco LF, Binder PS. What happens to the corneal transplant endothelium after penetrating keratoplasty? Cornea 2014 Jun;33(6):587-596.

59. Langenbucher A, Seitz B, Nguyen NX, Naumann GO. Corneal endothelial cell loss after nonmechanical penetrating keratoplasty depends on diagnosis: a regression analysis. Graefes Arch Clin Exp Ophthalmol 2002 May;240(5):387-392.

60. Seitz B, Langenbucher A, Nguyen NX, Kus MM, Küchle M, Naumann GO. Graft endothelium and thickness after penetrating keratoplasty, comparing mechanical and excimer laser trephination: a prospective randomised study. Graefes Arch Clin Exp Ophthalmol 2001 Jan;239(1):12-17.

61. Sarnicola V, Toro P, Sarnicola C, Sarnicola E, Ruggiero A. Long-term graft survival in deep anterior lamellar keratoplasty. Cornea 2012 Jun;31(6):621-626.
62. Reinhart WJ, Musch DC, Jacobs DS, Lee WB, Kaufman SC, Shtein RM. Deep anterior lamellar keratoplasty as an alternative to penetrating keratoplasty a report by the American Academy of Ophthalmology. Ophthalmology 2011 Jan;118(1): 209-218.

63. Azar RG, Holdbrook MJ, Lemp M, Edelhauser HF. Twoyear corneal endothelial cell assessment following INTACS implantation. J Refract Surg 2001 Sep-Oct;17(5):542-548.

64. Wollensak G, Spoerl E, Wilsch M, Seiler T. Endothelial cell damage after riboflavin-ultraviolet - a treatment in the rabbit. J Cataract Refract Surg 2003 Sep;29(9):1786-1790.

65. Carballo-Alvarez J, Puell MC, Cuiña R, Diaz-Valle D, Vazquez JM, Benitez-Del-Castillo JM. Soft contact lens fitting after intrastromal corneal ring segment implantation to treat keratoconus. Cont Lens Anterior Eye 2014 Oct;37(5):377-381.

66. Rathi VM, Mandathara PS, Taneja M, DumpatiS, Sangwan VS. Scleral lens for keratoconus: technology update. Clin Ophthalmol 2015 Oct 28;9:2013-2018.

67. Alfonso JF, Lisa C, Fernández-Vega L, Madrid-Costa D, PooLópez A, Montés-Micó R. Intrastromal corneal ring segments and posterior chamber phakic intraocular lens implantation for keratoconus correction. J Cataract Refract Surg 2011 Apr;37(4):706-713.

68. Coskunseven E, Onder M,Kymionis GD, Diakonis VF, ArslanE, Tsiklis N, Bouzoukis DI, Pallikaris I. Combined Intacs and posterior chamber toric implantable Collamer lens implantation for keratoconic patients with extreme myopia. Am J Ophthalmol 2007 Sep;144(3):387-389.

69. El-Raggal TM, Abdel Fattah AA. Sequential Intacs and Verisyse phakic intraocular lens for refractive improvement in keratoconic eyes. J Cataract Refract Surg 2007 Jun;33(6):966-970.

70. Coscarelli S, Ferrara G, Alfonso JF, Ferrara P, Merayo-Lloves J, Araújo LP, Machado AP, Lyra JM, Torquetti L. Intrastromal corneal ring segment implantation to correct astigmatism after penetrating keratoplasty. J Cataract Refract Surg 2012 Jun;38(6):1006-1013.

71. Barbara R, Barbara A. Intrastromal corneal ring segment with and without collagen corneal crosslinking vs penetrating keratoplasty for the treatment of keratoconus - case series. Int J Kerat Ect Cor Dis 2014 May-Aug;3(2):88-94.

72. Barbara A, Barbara R. Intacs intracorneal ring segments complications in patients suffering from keratoconus. Int J Kerat Ect Cor Dis 2013 Sep-Dec;2(3):121-128.

73. Bahar I, Kaiserman I, McAllum P, Rootman D, Slomovic A. Subconjunctival bevacizumab injection for corneal neovascularization in recurrent pterygium. Curr Eye Res 2008 Jan;33(1):23-28.

74. Bahar I, Kaiserman I, McAllum P, Rootman D, Slomovic A. Subconjunctival bevacizumab injection for corneal neovascularization. Cornea 2008 Feb;27(2):142-147.

75. Rodrigues P, Ferrara G, Ferrara P, Dias W, Torquetti L. Intrastromal corneal ring segments implantation in patients with mild keratoconus. Int J Kerat Ect Cor Dis 2014;3(3): 122-126.

76. Torquetti L, Ferrara G, Ferrara P. Predictors of clinical outcomes after intrastromal corneal ring segments implantation. Int J Kerat Ect Cor Dis 2012;1(1):26-30.

77. Khan MI, Injarie A, Muhtaseb M. Intrastromal corneal ring segments for advanced keratoconus and cases with high keratometric asymmetry. J Cataract Refract Surg 2012 Jan;38(1):129-136. 